УДК 336.71

\title{
ФАКТОРЫ, ВЛИЯЮЩИЕ НА СТРУКТУРУ КАПИТАЛА КОММЕРЧЕСКИХ БАНКОВ КНР
}

\section{Шэнь Бинбин аспирант}

Перфильев Александр Александрович

к. т. н, доцент

Новосибирский государственный университет

\begin{abstract}
Аннотация: Перед лицом все более жесткой рыночной конкуренции и давления финансового регулирования, если китайские коммерческие банки хотят и дальше повышать свою международную конкурентоспособность и прибыльность, рациональное распределение структуры капитала имеет решающее значение, а ключом к рациональному распределению структуры капитала является определение факторов, влияющих на структуру капитала Таким образом, анализ факторов, влияющих на структуру коммерческого капитала, и использование механизма накопления внутреннего капитала и внешних источников финансирования для увеличения банковского капитала является практической задачей, стоящей перед банковским сектором. В этой статье обобщается финансовая литература по существующей структуре капитала, обобщаются характеристики структуры капитала существующих китайских коммерческих банков на основе исторического процесса развития структуры капитала китайских коммерческих банков, а также анализируются факторы, влияющие на структуру капитала коммерческих банков как с внутренней, так и с внешней точки зрения.
\end{abstract}

Ключевые слова: коммерческий банк; структура капитала; коэффициент достаточности капитала. 


\title{
FACTORS THAT INFLUENCE CAPITAL STRUCTURE OF COMMERCIAL BANKS OF CHINA
}

\section{Shen Bingbing Perfilyev Alexander Aleksandrovich}

\begin{abstract}
Faced with increasingly severe market competition and financial regulatory pressures, if Chinese commercial banks want to further enhance their international competitiveness and profitability, the rational allocation of capital structure is crucial, and the key to rational allocation of capital structure is the determination of capital structure influencing factors Therefore, analyzing the influencing factors of commercial capital structure and using the mechanism of internal capital formation and external financing sources to increase bank capital is a practical problem facing the banking industry. This paper summarizes the financial literature on existing capital structure, summarizes the characteristics of the capital structure of existing Chinese commercial banks from the historical process of the capital structure development of Chinese commercial banks, and analyzes the influencing factors of the capital structure of commercial banks from the internal and external perspective of commercial banks.
\end{abstract}

Key words: commercial bank; capital structure; capital adequacy ratio.

\section{Введение}

На современном этапе, разворачивается процесс отхода от глобализации и попытки государств укрепить свою прежде всего экономическую устойчивость. На эти процессы повлияли ожидания глобального экономического кризиса и разворачивающаяся на наших глазах пандемия коронавируса. Эта новая реальность требует пересмотра и анализа моделей национальных экономик, которые в ближайшем будущем должны будут ориентироваться, в основном, на свои силы. В этом смысле, для КНР важно создать такую банковскую систему, которая будет способствовать развитию экономики, противостоять финансовым шокам, сохранять свою устойчивость. В этом контексте, исследование структуры капитала, которое концентрировалось в основном на развитие классических теорий и факторном анализе, на взгляд автора, должно изменить исследовательский фокус. По нашему мнению, следует уделить больше внимания, определению оптимальной структуры капитала, которая в наибольшей степени будет способствовать 
выполнению коммерческими банками своих основных функций и определению способов по формированию такой структуры.

\section{Теоретические основы предыдущих исследований структуры капитала банков}

Ukaegbu и Oino использовали выборку из 56 публично зарегистрированных коммерческих банков из десяти развивающихся стран, выяснилось, что стандартные детерминанты структуры капитала имеют объяснительную силу при объяснении отклонений в банковском капитале выше минимального требования. Что касается банков в развивающихся странах, исследование обнаруживает положительную связь между размером и балансовым и рыночным левериджем [1, с. 97].

Akhtar, Kayani и Yousaf изучали влияние структуры капитала на показатели деятельности иорданских банков. В исследовании использовалась годовая финансовая отчётность 12 коммерческих банков, зарегистрированных на Амманской фондовой бирже с 2007 по 2011 год, и использовалась модель множественной регрессии для оценки взаимосвязи между структурой капитала и эффективностью банков. Результаты показывают, что: чистая прибыль (NP), рентабельность чистых активов (ROE) и рентабельность чистого процента (NIM), измеряемые показателями банковской деятельности, имеют значительную положительную корреляцию со структурой капитала [2, с. 142].

Sickles дал понимание методологии границы как инструмента для измерения эффективности. В частности, оцените взаимосвязь между эффективностью фирмы, распределением капитала и риском, используя данные по большой выборке банков США за период с 2001 по 2016 год. Это исследование учитывает эндогенность принятия решений о рисках и капитале при производстве продукции и имеет важные последствия для банков и других организаций [3, с. 262].

Zhu Bingxia выбрала 14 коммерческих банков, зарегистрированных на бирже после 2004 года. Вывод исследования заключается в том, что взаимосвязь между размером банка и структурой банковского капитала незначительна, рентабельность, риск активов и ставка налога на прибыль существенно отрицательно связаны со структурой банковского капитала [4, с. 37].

Tan Zhengxun и Huang Dongsheng выбрали ежемесячные данные за период с 1999 по 2012 год для эмпирического анализа соотношения активов и пассивов китайских коммерческих банков в связи с макроэкономическими 
изменениями. В период экономического подъёма основными факторами, влияющими на коэффициент левериджа, являются межбанковские процентные ставки и доходность облигаций. [5, с. 23].

В настоящее время проводится множество исследований по структуре капитала коммерческих банков. Есть много направлений, которые можно исследовать. Можно сделать следующие выводы: на основе анализа разных научных работ мы пришли к выводу, что для КНР важно, чтобы коммерческие банки увеличивали свою эффективность за счёт грамотного управления привлечением и размещением денежных средств, оказанием банковских услуг. Проблемы агентских конфликтов не приобрели особой остроты в силу понимание китайскими специалистами важности развития страны и экономики.

\section{Специфика структуры капитала коммерческого банка КНР}

По сравнению с обычными предприятиями структура капитала коммерческих банков КНР имеет некоторые различия по сравнению с обычными предприятиями, что может быть отражено в следующих моментах:

(1) Важная роль коммерческого банка - это финансовый посредник. Его финансовая функция заключается в привлечении депозитов и выдаче кредитов. Он в основном опирается на обязательства для получения выгод. Коммерческие банки хотят более эффективно использовать функции рыночных посредников. Необходимым инструментом является высокий финансовый рычаг [6, с. 42]. Таким образом, активы коммерческих банков неизбежно будут иметь более высокий коэффициент задолженности, чем обычные предприятия, а доля капитала, принадлежащая акционерам, в общих активах коммерческих банков очень мала.

(2) Текущий состав долга коммерческих банков в основном представляет собой комбинацию большого количества небольших депозитов. В отличие от обычных долговых договоров, держатели депозитов могут в любой момент попросить банк выплатить всю сумму вклада, а банки обычно пассивны. Банки не могут ограничивать или мешать клиентам снимать деньги, и случайное снятие средств со стороны вкладчиков может привести к недостаточной ликвидности банковских средств. Коммерческие банки должны иметь хороший кредит, если они хотят добиться стабильной работы. Как только активы банка имеют высокий коэффициент задолженности, а общая деятельность его активов имеет циклические характеристики, эти два условия будут создавать большие риски для всей деятельности банка, и возникнут сомнения в том, что у него будет погашение задолженности. Будет более серьёзно угрожать риском 
ликвидации и банкротства [7, с. 24].

(3) Коммерческие банки имеют очень сложную операционную систему: не только существуют тесные связи между банками и банками, но банки также тесно связаны с другими финансовыми институтами, что позволяет очень легко распространять финансовые риски по всей финансовой системе и в конечном итоге угрожать финансовым Общая стабильность системы [8, с. 35]. Чтобы по возможности избежать такого рода рисков, различные страны и международные финансовые институты создали соответствующие организации и департаменты, а также разработали ряд систем, таких как страховые депозиты, системы подготовки средств и ограничения на инвестиции банков в рискованные активы, чтобы минимизировать вероятность риска [9, с. 30].

\section{Анализ структуры капитала 200 банков КНР}

Наша база содержит данные о 200 банков, в ней естественно есть отдельные пропуски, где банки не сообщали о своих данных, поэтому мы потратили много времени на корректную обработку. Выводы:(1) Политические банки изначально не настроены на работу с мелкими вкладчиками, поэтому там доля депозитов стабильно низкая. Политические банки основную часть ресурсов размещают в кредитах, реализуется через участие в капитал крупных государственных или политически важных частных компаний. (2) Доля собственного капитала варьирует в узком диапазоне у сельхозбанков, что объясняется динамикой рисковых активов. Портфель ценных бумаг может служить источником для быстрого предоставления заёмщиком кредитов, что важно для фермеров и сельских жителей. (3) Государственные банки сохраняют долю кредитов постоянной. Государственные банки рассматриваться вкладчиками как наиболее надёжные для хранения сбережений. (4) Акционерные банки, в условиях роста внешней нестабильности восприниматься как менее надёжные источники для хранения денег, поэтому там размер депозитов сокращается.

\section{Регрессионный анализ структуры капитала акционерных банков КНР}

В работе используется программное обеспечение Eviews для анализа панельных данных 16 акционерных банков с первого квартала 2014 года по четвёртый квартал 2018 года. Модель как следующий:

$$
\begin{aligned}
& \operatorname{Lev}_{\mathrm{i}, \mathrm{t}}=\beta_{0}+\beta_{1} \ln (\text { size })_{\mathrm{i}, \mathrm{t}}+\beta_{2} \mathrm{ROE}_{\mathrm{i}, \mathrm{t}}+\beta_{3}(\text { Losses on assets })_{\mathrm{i}, \mathrm{t}}+\beta_{4}(\text { Reserves })_{\mathrm{i}, \mathrm{t}} \\
& \left.+\beta_{5} \mathrm{CAR}_{\mathrm{i}, \mathrm{t}}+\beta_{6} \text { (Taxit on profit }\right)_{\mathrm{i}, \mathrm{t}}+\beta_{7}(\mathrm{GDP})_{\mathrm{i}, \mathrm{t}}+\beta_{8}(\mathrm{CPI})_{\mathrm{i}, \mathrm{t}} \\
& +\mathrm{u}_{\mathrm{i}, \mathrm{t}} \\
& \mathrm{i}=1,2,3,4 \cdots 16 \quad \mathrm{t}=1,2,3,4,5 \cdots 20
\end{aligned}
$$


Таблица 1

Результаты регрессионного анализа EViews 8.0

\begin{tabular}{|c|c|c|}
\hline факторы & показатель & корреляция \\
\hline & $\begin{array}{l}\mathrm{Y}=1-\text { (балансовая собственного } \\
\text { капитала / балансовая стоимость } \\
\text { активов) }\end{array}$ & \\
\hline \multirow[t]{6}{*}{ Внутренние } & $\mathrm{X} 1=\ln$ (Total assets) & Отрицательная \\
\hline & $\mathrm{X} 2=\mathrm{ROE}$ & Положительная \\
\hline & $\begin{array}{l}\mathrm{X} 3=\text { Impairment losses on assets/Total } \\
\text { assets } \times 100 \% \text {. }\end{array}$ & Отрицательная \\
\hline & $\begin{array}{l}\mathrm{X} 4=(\text { Стоимость основных средств } / \\
\text { Стоимость общих активов }) \times 100 \% .\end{array}$ & Отрицательная \\
\hline & X5 = Capital adequacy ratio. & Отрицательная \\
\hline & $\begin{array}{l}\text { Х6 = Расходы по налогу на прибыль / } \\
\text { общая прибыль× 100\%. }\end{array}$ & Положительная \\
\hline \multirow[t]{2}{*}{ Внешние } & $\begin{array}{l}\text { X7 = ежеквартальное процентное } \\
\text { изменение ВВП }\end{array}$ & Положительная \\
\hline & $\begin{array}{l}\text { X8= ежегодное процентное изменение } \\
\text { индекса средних потребительских цен }\end{array}$ & Положительная \\
\hline
\end{tabular}

Программа EViews 8.0 позволила нам получить следующие результаты на значительном уровне $5 \%$ (табл. 1 ), положительно коррелируют $\mathrm{X} 2$ (коэффициент рентабельности собственного капитала), Х6 (коэффициент налога на общая прибыль), X7 (уровень макроэкономического развития) ,X8 (уровень инфляции) и Y (кредитное плечо банка);X1 (совокупные активы), X3 (убытки от обесценения активов), X4 (величина гарантии активов), X5 (коэффициент достаточности капитала) и Y (кредитное плечо банка) имеют отрицательную корреляцию.

Таблица 2

\section{Влияние Xi на Y 16 коммерческих банков по R-studio}

\begin{tabular}{|l|l|l|l|l|l|l|l|l|}
\hline & r. s1 & r. s2 & r. s3 & r. s4 & r. s5 & r. s6 & r. s7 & r. s8 \\
\hline 1 & 0.7511 & 0.0411 & 0.1917 & 0.6473 & 0.0459 & 0.9445 & 0.5670 & 0.5007 \\
\hline 2 & 0.2870 & 0.9711 & 0.4704 & 0.7732 & 0.8307 & 0.4109 & 0.4941 & 0.8511 \\
\hline 3 & 0.7433 & 0.3705 & 0.7381 & 0.8762 & 0.0239 & 0.2301 & 0.5189 & 0.8854 \\
\hline
\end{tabular}




\begin{tabular}{|c|c|c|c|c|c|c|c|c|}
\hline 4 & 0.5330 & 0.1255 & 0.9134 & 0.9920 & 0.6959 & 0.1754 & 0.4135 & 0.1780 \\
\hline 5 & 0.7714 & 0.2195 & 0.2387 & 0.7889 & 0.4315 & 0.9315 & 0.8657 & 0.2958 \\
\hline 6 & 0.3867 & 0.6039 & 0.3117 & 0.4124 & 0.1883 & 0.2867 & 0.5535 & 0.5535 \\
\hline 7 & 0.2414 & 0.9661 & 0.9692 & 0.0488 & 0.1727 & 0.7728 & 0.7883 & 0.6683 \\
\hline 8 & 0.7773 & 0.5654 & 0.3869 & 0.9250 & 0.0059 & 0.0207 & 0.0633 & 0.2076 \\
\hline 9 & 0.9726 & 0.2620 & 0.0673 & 0.2320 & 0.0063 & 0.2481 & 0.5845 & 0.3754 \\
\hline 10 & 0.2411 & 0.4070 & 0.1435 & 0.0581 & 0.0003 & 0.0025 & 0.0092 & 0.0882 \\
\hline 11 & 0.3011 & 0.5949 & 0.9588 & 0.2238 & 0.5414 & 0.1489 & 0.8455 & 0.8733 \\
\hline 12 & 0.1893 & 0.5398 & 0.3126 & 0.3007 & 0.1386 & 0.5498 & 0.4273 & 0.8252 \\
\hline 13 & 0.0423 & 0.0010 & 0.1783 & 0.1496 & 0.2350 & 0.2330 & 0.0034 & 0.1591 \\
\hline 14 & 0.3760 & 0.9834 & 0.9470 & 0.6301 & 0.4795 & 0.0036 & 0.1314 & 0.8946 \\
\hline 15 & 0.6833 & 0.4299 & 0.0659 & 0.3974 & 0.0011 & 0.1645 & 0.3908 & 0.6214 \\
\hline 16 & 0.6583 & 0.4596 & 0.0538 & 0.2574 & 0.6234 & 0.0361 & 0.1507 & 0.5203 \\
\hline
\end{tabular}

Были построены регрессии для каждого банка (табл. 2). Анализ показал, что отсутствует явная тенденция в объяснении финансового рычага для разных типов банков, но наблюдается определенная специфика. Обратим внимание на банк ICBC. Он является крупнейшим банком КНР, с большой долей государства в акционерном капитале и сильной государственной поддержкой. Как из видно из рисунка, ни один из выбранных факторов не является значимым для его структуры капитала. Это является очевидным, учитывая его особенности.

Размер активов (X1) показал разное влияние в банках независимо от их размера, хотя 70 \% банков показали сильную зависимость от этого фактора. ROE - фактор X2 имеет ярко выраженную высокую значимость для малых и средних акционерных банков, для больших банков - он не играет важного значения для структуры капитала. Так, фактор ВВП (X7) оказывает значимым для небольших банков, клиенты которых - малые и средние предприятия, которые в последнее десятилетие обеспечивали рост ВВП и их деятельность сильно зависит от экономики. Для больших банков этот фактор не является важным. Фактор инфляции имеет значение для структуры капитала больших банков $(1,2,3,12,14)$. Кроме того, одни и те же факторы влияют на финансовый рычаг разнонаправленно, что требует отдельного анализа.

\section{Выводы}

Во-первых, в этой статье используются анализ и индукция в сочетании с отечественной и зарубежной исследовательской литературой для обобщения 
факторов, влияющих на структуру капитала коммерческих банков. Выводы нашего исследования почти совпадают с результатами, полученными китайскими учеными за последние пять лет. Однако наш анализ показывает, что эти показатели по-разному влияют на разные типы банков. Для крупных и системно значимых банков решающее значение имеют макроэкономические и инфляционные факторы, в то время как для малых и средних банков эти влияющие факторы не имеют большого значения.

Во-вторых, выявлено, что многие факторы, влияющие на структуру капитала коммерческих банков КНР, совпадают с факторами, выявленными западными учёными, которые изучали банковские системы развитых экономик. Это позволяет говорить о том, что банковская система КНР приобретает черты современного финансового института.

В-третьих, по данным расчётов по регрессионной модели выяснило, что ряд факторов, связанных с макроэкономическими факторами, не влияет на уровень финансового рычага банков, хотя по данным научных работ, эти параметры оказывались важными для развитых стран. Мы думаем, что это связано с большим ростом китайской экономики и ожиданиями дальнейшего роста. В таких условиях восприимчивость рычага и ВВП не очевидна. Были построены регрессии для каждого банка. Анализ показал, что отсутствует явная тенденция в объяснении финансового рычага для разных банков. Кроме того, одни и те же факторы влияют на финансовый рычаг разнонаправленно, что требует отдельного анализа. Можно сделать вывод о том, что адаптация банков к рыночным условиям происходит с разной скоростью и имеет свою специфику.

\section{Список литературы}

1. Ukaegbu B., Oino I. The determinants of capital structure in a regulatory industry: The case of Kenyan banks // Banks Bank Syst. 2013. T. 8. № 1. C. 97-111.

2. Akhtar Y., Kayani G.M., Yousaf T. The Effects of Regulatory Capital Requirements and Ownership Structure on Bank Lending in Emerging Asian Markets // J. Risk Financ. Manag. 2019. T. 12. № 3. C. 142.

3. Ding D., Sickles R.C. Frontier efficiency, capital structure, and portfolio risk: An empirical analysis of U.S. banks // BRQ Bus. Res. Q. 2018. T. 21. № 4. C. 262-277.

4. Zhu Bingxia. Эмпирическое исследование факторов, влияющих на структуру капитала китайских коммерческих банков. // 2012. С. 37-39. 
5. Tan Zhengxun H.D. Микро-факторы, влияющие на стабильность коммерческих банков. // Финансовый форум. 2012. Т. 17. № 01. С. 23- $28+45$.

6. Chunhong J. The Empirical Research on China's Commercial Bank Efficiency. Liaoning, China.2014. 42-121 c.

7. Gao Shujie. Research on Profitability and Credit Risk Management of Chinese State-owned Commercial Banks. Jilin, China.2020. 24-42 c.

8. He Kai. The Empirical Research on Bank Efficiency of Chinese City Commercial Bank. Chengdu, Sichuan, China.2014. 35-49 c.

9. Duanyang Z. Study on the Factors of Profit-making Ability of China's Listed Commercial banks. Yunnan, China.2018. 30-54 c.

(C) Б. Шэнь, А.А. Перфильев, 2021 